\title{
Late Radiation Injury
}

National Cancer Institute

\section{Source}

National Cancer Institute. Late Radiation Injury. NCI Thesaurus. Code C3665.

Late radiation injury (LRI) is the damage to the soft tissue and bone following radiation therapy that occurs weeks and years after the radiation exposure. Pathogenesis of LRI stems from ischemia, interruption of the blood supply and direct cell damage. LRIs include but not limited to the skin atrophy, ulceration and non-healing wounds; cystitis, proctosigmoiditis, resulting to fistulas, abscesses, fibrosis and scaring; laryng itis, osteoradionecrosis; central nervous system injury, optic neuropathy. 